\title{
EDUCATING MOTHERS TO SCREEN CARIES IN THEIR SPECIAL-HEALTH-CARE-NEEDS CHILDREN
}

\author{
Dalia Moheb*, Samah Awad* and Mervat Rashed*
}

\begin{abstract}
Aim: To consider the ability of mothers to screen caries in their special health care needs (SHCN) children after attending an educational training program.

Subjects \& Methods: A study involving 100 mothers of SHCN children aged 4-6 years old seeking treatment at the general anesthesia unit of Egyptian Society for Pediatric Dentistry and Children with Special Needs (ESPSN)-Faculty of Oral and Dental Medicine-Cairo University. Mothers of SHCN children were trained in a 3 hours training program by the researchers to detect caries in their children using power point presentations, and flash cards. Mothers were trained to screen caries according to the WHO (1997) criteria for caries diagnosis. After the training program, all mothers performed caries screening on their own children. The findings were checked for validity by comparing mothers' findings with researchers' findings as the gold standard.

Results: The overall prevalence of caries in the sample was $90 \%$. The sensitivity, specificity, positive predictive value and negative predictive value of mothers' caries screening were $94.4 \%$, $70.0 \%, 90.8 \%$ and $81.5 \%$ respectively.

Conclusions: It was feasible to train mothers with basic skills to screen dental caries in their special health care needs children. This prospect might provide a substantial future venue, giving mothers of children with SHCN a chance to seek dental treatment early and thus avoid further complications and extensive treatment.
\end{abstract}

\section{INTRODUCTION}

Dental decay continues to be a significant public health issue that is worthy of acknowledgment due to its widescale existence, costly treatment and management, and it being a principal cause of oral pain and tooth loss which leads to the deterioration of the quality of life of those suffering from it ${ }^{(1,2)}$.
Despite the fact that there has been a notable global decline in its occurrence ever since the start of the 1970s, alarming disease levels have still been reported by a smaller section of individuals, labeled as high caries risk individuals ${ }^{(3)}$. The term "high caries risk" denotes a child who is either at risk of developing excessive levels of dental caries or is at risk of the concerning results of caries, including the

\footnotetext{
* Pediatric Dentistry Cairo University
} 
ones who are in danger by virtue of their medical, psychological or societal, i.e. the ones who are in danger of or from caries ${ }^{(4)}$.

Early Childhood Caries (ECC) is still considered a majorly critical public health concern in developing countries and among the lower socioeconomic groups of a nation. It remains a challenge to the dental health care sector of developing and developed countries all over the globe despite the significant progress made in the fields of pathogenesis and prevention of dental caries throughout the past two decades as reports of occurrence of caries in preschool students is still on the rise ${ }^{(5)}$.

In our society, there are distinctive groups who should be provided and handled with a more urgent level of attention than those of the general community. For instance, the mentally handicapped and physically challenged pre-school youngsters who are threatened by caries and periodontal disease. Handicapped children often suffer from several health issues due to their bodily and/or mental restrictions, therefore it is unfortunately true that they neglect their oral health care issues, as they believe that it is of lower priority due to the other major issues threatening their wellbeing. However, if superior quality of life is desired for this group, then it is a must to ensure that the protection and maintenance of decent oral health care is a vital part of their general comfort and welfare ${ }^{(6,7)}$

One of the major principals in oral health care is the preservation of good oral sanitation, which is logically a huge challenge to a physically or mentally handicapped independent individual. Thus, support is then essential from the parents, caretakers, and educators, who may be oblivious of what is the proper oral hygiene preservation and of its vital role in health care, and therefore may not be able to provide sufficient aid. Consequently, those challenged individuals, whether mentally or physically so tend to adopt an inadequate oral hygiene routine, which only leads to severe and serious oral health issues and oral hygiene deterioration as they age when compared to the normal group of the community ${ }^{(6,8)}$.

Children who suffer from any form of special needs; psychological, physical or even mental ones should be encouraged to be part of a special precautionary care routine supervised by a dental clinic ${ }^{(9)}$. Due to the limitations those children suffer from, and their sometimes difficult and uncooperative attitudes, they usually are reliant on their parents, guardians, or clinical assistants when it comes to the implication of their oral health care routines ${ }^{(10)}$. That is why any precautionary schemes for those challenged youngsters should include thorough programs to raise awareness, motivate the children and support their caretakers to achieve a decent and acceptable level of oral hygiene during their lifespan, eventually leading to higher quality of life ${ }^{(11,12)}$.

The vast majority of recent recommendations have a shared pillar: early recognition of high caries risk children for an early introduction of protective actions ${ }^{(4)}$. This requires the remodeling of the dental services to target a younger age group than its current target - i.e. preschool children. However, early school and pre-school handicapped youngsters are yet to receive the treatment and care they require, especially in developing countries.

It is a hard fact that parents of high-risk children usually take action after the caries in primary teeth had progressed and become irritatingly symptomatic. Unfortunately, the only possible action left to a dentist then is an invasive treatment, and still parents tend to neglect subsequent visits until the same extreme scenario occurs again with their child (14). That is why parents should be motivated to be part of the decision procedures used to help manage unwell children ${ }^{(15)}$. Mothers play a vitally critical role as they transmit their behavior to their children, therefore it is of crucial importance to increase their understanding about the positive attitude they need 
to transmit to their youngsters inevitably leading them to the better desired oral health ${ }^{(16)}$.

It is established that handicapped children are faced with numerous obstacles when it comes to their oral care, which leaves them with a higher tendency of suffering from oral diseases. Mothers in our community play a crucial part that they should use to stimulate and achieve oral wellbeing. Mothers are the ones who dictate whether their children need to pay the dentist a visit or not ${ }^{(17)}$. That is why the cooperation between dentists and mothers is a vital step to achieve the desirable high quality of life those children deserve.

\section{Objective}

To consider the ability of mothers to screen caries accurately in their special health care needs (SHCN) children after attending an educational training program.

\section{SUBJECTS AND METHODS}

We sought to compare independent, blinded oral screening results made by mothers of special health needs children with those of a pediatric dentist, considered for purposes of the study to be the reference gold standard.

Participants: The study involved 100 mothers of $(S H C N)$ children aged $4-6$ years old seeking treatment at the general anesthesia unit of Egyptian Society for Pediatric Dentistry and Children with Special Needs (ESPSN)-Faculty of Oral and Dental Medicine-Cairo University. The present study was conducted during the period from October 2014 to January 2015.

Mothers included in the study had children that suffered disabilities (cerebral palsy, mental retardation, Down syndrome, autism, hearing \& speaking disorders and visual impairment). Information regarding the demographic backgrounds, educational level, feeding habits, oral hygiene practices was collected from all the mothers.
Mothers of children with serious acute health condition that would disallow their full participation were excluded from the study. Only mothers that approved to participate in the study and gave informed consents were included in the study. Illiterate mothers were not included in the study.

A training program was specially designed for that purpose that was simple and directed to basics of dental caries screening. The three hours training was carried out by one of the researchers utilizing flash cards and power point presentation in the Pediatric Dentistry Department Faculty of Dental Medicine Cairo University. Clinical slides illustrated dental caries in various stages of progression. Specific instructions were given on how to recognize a cavitated carious lesion.

Mothers of SHCN children were trained to detect caries in their children. Mothers were trained to screen caries according to the WHO (1997) criteria for caries diagnosis. After the training program, all mothers performed caries screening on their own children. The diagnosis of dental caries was undertaken by visual examination using disposable dental mirrors utilizing the criteria recommended by world health organization.

Both the pediatric dentist and the mother of the special health needs child conducted a dental screening on each child and recorded carious teeth on a specially designed chart.

The findings were checked for validity by comparing mothers' findings with researchers' findings as the gold standard. Caries diagnosis was carried out by an independent researcher who was blind to the mothers' diagnosis. Data were then statistically analyzed to determine the accuracy of the mothers' findings.

\section{Statistical Analysis}

Accuracy was represented using the terms sensitivity, specificity, +ve predictive value, -ve predictive value, and overall accuracy. Comparing 
accuracy was done using Yates corrected Chi squared test. $p$ values less than 0.05 was considered statistically significant. All statistical calculations were done using computer program SPSS (Statistical Package for the Social Science; SPSS Inc., Chicago, IL, USA) version 15 for Microsoft Windows.

\section{RESULTS}

Most of the mothers in the present study had only their primary education. One hundred mentally impaired and physically disabled children (67 boys and 33 girls) were dentally examined. The age range was 4 to 6 years with a mean age of 4.6 years. The types of handicapping conditions observed during examinations are seen in Table I.

TABLE (I) Types of handicapping conditions and their number in the studied group

\begin{tabular}{|l|l|}
\hline Condition & Number \\
\hline Cerebral palsy & 32 \\
\hline Down syndrome & 22 \\
\hline Autism & 14 \\
\hline Mental retardation & 20 \\
\hline Hearing \& speaking problems & 9 \\
\hline Visual impairment & 3 \\
\hline
\end{tabular}

Only $10 \%$ of the children were caries free i.e. caries prevalence in the examined children was $90 \%$ $(n=100)$.

Tooth-Level Analysis: Total number of teeth examined was 1980 teeth, total number of decayed teeth was 1500 teeth with 480 caries free teeth.

\section{Accuracy of mothers' screening:}

The reference standard was the diagnosis carried out by the blinded investigator. The mothers' screening results showed sensitivity of $94.4 \%$ which indicates the ability to correctly identify a condition when it truly existed i.e. true positive rate when their screening results for individual teeth were compared with the gold standard. Sensitivity $=$ True positive counts/ (true positive+ false negative)

The specificity of mothers' screening results which is the true negative rate was $70 \%$, this indicates the ability to accurately identify the negatives as such when their screening results for individual teeth were compared with the gold standard. Specificity $=$ True Negative counts $/$ (true negative + false positive)

Mothers' screening results showed positive predictive value of $90.8 \%$ and negative predictive value of $81.5 \%$ which may indicate that mothers tended to misdiagnose caries free teeth.

Positive predictive value $=$ True positive $/($ True positive+ false positive)

Negative predictive value $=$ True negative $/$ (True negative + false negative)

The mothers' screening results included 76 falsenegative teeth on the other hand their screening results showed 144 false positive results. Thus, mothers tended to over-count the number of sound teeth as carious.

TABLE (II) Showing mothers' screening results of their children's teeth

\begin{tabular}{|l|l|l|}
\hline & $\begin{array}{l}\text { Condition } \\
\text { positive }\end{array}$ & $\begin{array}{l}\text { Condition } \\
\text { negative }\end{array}$ \\
\hline $\begin{array}{l}\text { Test outcome } \\
\text { positive }\end{array}$ & $\begin{array}{l}\text { True positive } \\
1424\end{array}$ & $\begin{array}{l}\text { False positive } \\
144\end{array}$ \\
\hline $\begin{array}{l}\text { Test outcome } \\
\text { negative }\end{array}$ & $\begin{array}{l}\text { False negative } \\
76\end{array}$ & $\begin{array}{l}\text { True negative } \\
336\end{array}$ \\
\hline
\end{tabular}



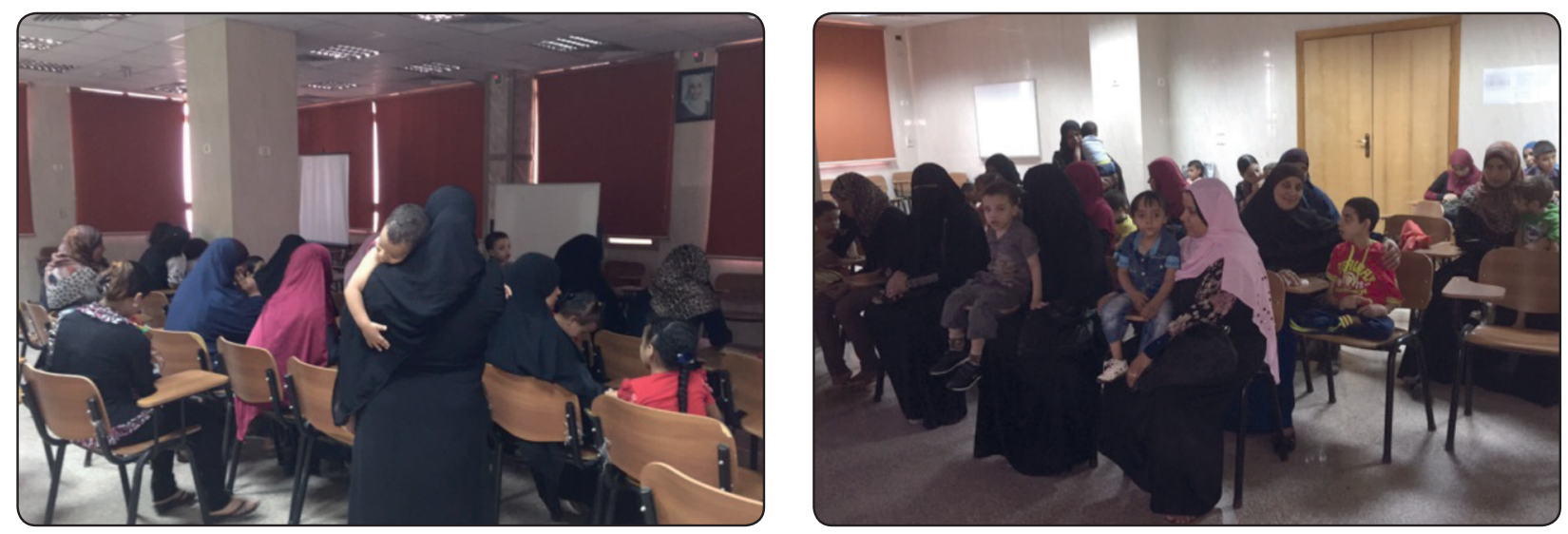

Fig. $(1,2)$ : Showing mothers in the training classes.

\section{DISCUSSION}

There are reasons to believe that the ratio of disabled people to the general population is noticeably increasing, yet dental health care remains the most mutual unsatisfied need of that proportion of handicapped children ${ }^{(18)}$. In the present study the caries prevalence on the studied group was $90 \%$. This may be explained by the fact that challenged youngsters and adolescents tend to have inferior oral hygiene and health when compared to non-disabled individuals of the same age group. Some of the reasons behind that fact could include inconsistent access to oral care, poor dental hygiene and several disability-related limitations. This comes in accordance with Francis et al., ${ }^{(19)}$ in their study on dental health and dental care of young handicapped adults the amount of untreated caries was much higher and the periodontal status was worse in the studied group when compared to what is expected in normal young adults in the same age group.

In the current study the department of Pediatric Dentistry Cairo University was selected because it serves a large number of handicapped patients and provides service for those children under general anesthesia through the Egyptian Society for Pediatric Dentistry and Children with Special Needs (ESPSN).
In the current study sample, the occurrence of dental caries was $90 \%$, which is very high. The previous fact could also be due to the low socioeconomic level of the studied sample as well as the fact that oral needs are of inferior priority when compared to their other health urgencies. These present results align with the studies by Shapira et al., ${ }^{(20)}$, Ulseth et al., ${ }^{(21)}$, Gupta et al., ${ }^{(22)}$, and Pope et al., ${ }^{(23)}$, which also show that challenged children, whether intellectually or physically, were found to have noticeably higher caries experience and/or greater stages of periodontal disease. Moreover, this study also comes in accordance with Ivan et al., (24) who also showed that the occurrence of caries in youngsters with disabilities was extremely high, in contrast with the number of children whose oral hygiene state was acceptable. In addition, Ajami et al., (25) also reached parallel conclusions when he studied the dental treatment needs of disabled youngsters.

One of the fundamentals of enhancing the oral health of young children according to The Irish Guideline Group (26) was the early identification of high caries risk children.

The current study's subjects involved mothers of preschool challenged youngsters in the age group of 4-6 years old as those were perceived a high-risk group. This aligns with the conclusions of 
Sagheri et al., ${ }^{(4)}$, which included that the highest chance of the primary prevention of dental disease is found in the young disabled children, not to mention that this group will also be able to help establish futuristic patterns.

The most frequent strategy in caries prevention is raising the awareness of the parents, yet the traditional health education might not be sufficient to convince the parents to make the needed change in their behavior when it comes to their high-risk children. One of the reasons of that would be that parents rarely seek out professionals in a state of willingness to change their established routines and behaviors ${ }^{(14)}$. Despite the fact that the value of the evidence proving the efficiency of oral health education when it comes to the prevention of Early Childhood Caries (ECC) is mostly weak and the outcomes are contradictory, early and recurrent connection with mothers before their children reach the age of two, especially in a non-clinic environment had proven to be of vital importance in preventive educational programs against caries in youngsters and this comes in alignment with the choice of mothers in the current study ${ }^{(27,28,30)}$.

It has been recommended by the Irish Oral Health Services Guideline Initiative (26) that public Health Nurses, practice nurses, General Practitioners and other chief primary care workers, who are regularly in touch with youngsters receive adequate training to help the early identification of high caries risk infants.

The reason behind the involvement of mothers in the study is due to their special position in relation with the special health care needed by their challenged children. This came in accordance with Rayner ${ }^{(30)}$ \& Farid et al. ${ }^{(17)}$ who concluded that mothers have the greatest influence on the dental health state and the oral hygiene routines of their children.

There is limited evidence for the efficiency of non-dental health professionals being able to identify high caries risk preschool children. A systematic review by Bader et al. ${ }^{(31)}$ assessed the accuracy of primary care takers at identifying children with dental caries of age range 0-5 years, as well as the referral to a dentist. The review acknowledged two studies of Serwint et al. ${ }^{(32)}$ and Beltran et al. ${ }^{(33)}$ in which main health care clinicians identified carious lesions with a correctness similar to that of a dentist. Also according to the study by Serwint et al. ${ }^{(32)}$ that compared the performance of a pediatrician after four hours of training with that of a "gold standard" pediatric dentist at the identification "nursing caries "in children aged 18-36 months. The pediatrician identified nursing caries with a sensitivity of $100 \%$ and a specificity of $87 \%$ compared to the gold standard (i.e. all the children with caries were correctly identified and $87 \%$ of children without caries were correctly identified as being caries free). The prevalence of nursing caries in the full sample was $20 \%$.

According to a study by Beltran et al. ${ }^{(33)}$, a nurse with the training of 5 hours in oral screening, using a flashlight and a tongue blade attained a sensitivity of $92.2 \%$ and a specificity of $99.3 \%$ in the identification of untreated decay in 219 children in the age group of 5-12 years old in comparison to the observational tactile inspection by a dentist.

In another study by Pierce et al. ${ }^{(34)}$, the accuracy of 11 pediatricians and one nurse specialist at inspecting and referring children in the age group below 36 months for early childhood caries was assessed following two hours training. The pediatricians and nurse specialist achieved 76\% when it came to sensitivity and a $95 \%$ of specificity in the identification of children with one or more cavitated primary teeth in comparison to a dentist.

Another argument made by Pierce et al. ${ }^{(34)}$ stated that primary health care workers should utilize their established access to infants and youngsters to play a major role in the prevention and control of early childhood, because unlike dentists they have wide 
contact with toddlers earlier on. However, there are limited studies on the efficiency and value of the oral screenings and referrals made by those primary health care workers when it comes to preventive procedures.

On a different note the prospective study carried out by Wendt et al. ${ }^{(35)}$ about whether the procedure of identification of dental caries in toddlers could be taught to their parents. The parents involved in the experimental group received training using a colored photo to be able to identify the primary signs of initial dental caries on buccal surfaces of the upper incisors. The study proposed that parents are not qualified to detect caries in their children, or at the very least they are unable to request guidance or dental treatment.

On the contrary, a study by Lee et al. ${ }^{(36)}$ showed otherwise. The study encouraged the approach to train non-dental workers to be able to identify early childhood caries. In their report 77 parents and health care workers of toddlers averaging 24.4 months old from four WIC clinics in King County, Washington, were requested to examine their own toddlers using a mirror and a brochure with diagrams about how caries develops after watching a five-minute video recording. More than $80 \%$ of the parents had similar responses as that of the dentists.

In the current study mothers were asked to examine their children after taking part of a threehour training program which comes in accordance with the average training times in the previous studies. Their results of screening were then compared to ones of a "gold standard" dentist.

The tools were utilized to be aligned with their intellectual and educational levels to be easily grasped, this comes in accordance with Wendt et al. ${ }^{(35)}$

The results of the current study show that the mothers had achieved sensitivity of $94 \%$ and specificity of $70 \%$. This may be aligned with
Lee et al. ${ }^{(36)}$ findings and contradicts Wendt et al. ${ }^{(35)}$. The results in the current study may be explained by the fact that the mothers in the study have higher level of medical exposure as the mothers of those children usually carry out numerous paramedical tasks for their children, which prepared with an adequate base for satisfactory dental education. The mothers' screening showed positive predictive value of $90.8 \%$ and negative predictive value of $81.5 \%$ which may indicate that mothers tended to misdiagnose caries free teeth. This contrasted Peirce et al. ${ }^{(34)}$, who suggested that the primary health caretakers tended to under-count the number of teeth with carious lesions.

The results of the current study signify that mothers of special health care needs children play a vital hand in the prevention of dental caries in those high-risk individuals. The current study results provide strategies to move patients from inaction to action and attempts to create an atmosphere in which the person can explore problems safely and face difficulty with realities

\section{CONCLUSIONS}

It was feasible to train mothers with basic skills to screen dental caries in their special health care needs children. This prospect might provide a substantial future venue, giving mothers of children with SHCN a chance to seek dental treatment early and thus avoid further complications and extensive treatment.

\section{REFERENCES}

1. Warren JJ, Weber-Gasparoni K, Marshall TA, Drake DR, Dehkordi-Vakil F, Dawson DV, Tharp KM: A longitudinal study of dental caries risk among very young low SES children. Community Dent Oral Epidemiol 2009, 37:116-122.

2. Ditmyer M, Dounis G, Mobley C, Schwarz E: A casecontrol study of determinants for high and low dental caries prevalence in Nevada youth. BMC Oral Health 2010, $10: 24$. 
3. Tagliaferro EP, Ambrosano GM, Meneghim Mde C, Pereira AC: Risk indicators and risk predictors of dental caries in schoolchildren. J Appl Oral Sci 2008, 16:408413.

4. Sagheri D(1), McLoughlin J, Nunn JH. Dental caries experience and barriers to care in young children with disabilities in Ireland. Quintessence Int. 2013 Feb; 44(2): 159-69. doi: 10.3290/j.qi.a28927.

5. Tsubouchi J, Tsubouchi M, Maynard R, Domoto P et aL A Study of dental caries and risk factors among native American infants. Journal of Dentistry for Children 1995;52:283-87.

6. O'Donnell D. The Medical-Dental Interfaces in the treatment of the Chronically sick child. Hong Kong Practitioner 1986 ; 8 ; i 810-1815.

7. O'Donnell D \& Crosswaite MA. Dental Health Education for the Mentally Handicapped Children. The Journal of the Royal Society of Health 1988;1:8-1O.

8. Brown JP. Dental care for the handicapped children. International Dental Journal 1980;30:14-27.

9. Mc Donald Re, Dr Avery, Odontoiatria per bambino e l'adolescente (Piccin, Padova, 1988).

10. Storhaug K, Nor Tannlaegeforen Tid, 101 (1991) 262.

11. Bortolotti L, Cetrullo L, Frezza R, Il Dentista Modreno, $10(1986)$

12. Palin-Palokas T, Hausen H, Heinonen I, Community Dent Oral Epidemiol, 15 (1987) 19.

13. Nunn J, Murray J. The dental health ofhandicapped children in Newcastle and Northumber . British DentalJournal 1987;162:9-12.

14. Weinstein P, Harrison R, Benton T. Motivating parents to prevent caries in their young children: One-year findings. J Am Dent Assoc 2004;135:731-8.

15. Oppenheim P I, Sotiropoulos G, Baraff L J. Incorporating patient preferences into practice guidelines: management of children with fever without source. Am J Emerg Med 1995; 26: 240-241

16. Manchanda K, Sampath N, De SarkarA. Evaluating the effectiveness of oral health education program among mothers with 6-18 months children in prevention of early childhood caries. Contemporary Clinical Dentistry I OctDec 2014 | Vol 5 | Issue 4
17. Farid H., Khan R F, Aman N. Mothers play a basic role in the dental health of children. They decide whether their children need dental treatment or not. J Ayub Med Coll Abbottabad 2013;25(3-4)

18. Francis JR, Stevenson DR, Palmer JD. Dental health and dental care requirements for young handicapped adults in Wessex. Community Dent Health 1991; 8:131-7.

19. Maclaurin ET, Shaw L, Foster TD. Dental study of handicapped children attending special school in Birmingham. Part II Dental cleanliness and periodontal treatment requirement. Community Dental Health 1985b; 2:259- 65.

20. Shapira J, Stabholz A, Schurr D, Sela MN, Mann J. Caries levels, streptococcus mutans counts salivary ph and periodontal treatment needs of adults Down syndrome patients. Special Care in Dentistry $1991 ; 11: 284-251$.

21. Ulseth JO, Hestnes A, Stovner U, Storhaug K. Dental caries and periodontitis in persons with Down syndrome. Special Care in Dentistry 1991 ; 11:7 1-73.

22. Gupta DP, Chowdhury R, Sarkar S. Prevalence of dental caries in handicapped children of Calcutta. Journal ofindian Society of Pedodontics and Preventive Dentistry 1993 ;11:23-27.

23. Pope JE, Curzon ME. The dental status of cerebral palsied children.Pediatric Dentistry 1991;13:156-162.

24. Ivan N, Joki,et al., Dental Caries in Disabled Children, Coll. Antropol. 31 (2007) 1: 321-324

25. Ajami BA, Shabzendedar M, Rezay MYA, Asgary M. Dental Treatment Needs of Children with Disabilities. JODDD, Vol. 1, No. 2, Summer 2007.

26. Irish Oral Health Services Guideline Initiative. Strategies to prevent dental caries in children and adolescents: Evidence-based guidance on identifying high caries risk children and developing preventive strategies for high caries risk children in Ireland (Full guideline). 2009

27. Feldens CA, Vitolo MR, Drachler Mde L. A randomized trial of the effectiveness of home visits in preventing early childhood caries. Community Dent Oral Epidemiol 2007;35(3):215-23.

28. Harrison R, Benton T, Everson-Stewart S, Weinstein P. Effect of Motivational Interviewing on Rates of Early Childhood Caries: A Randomized Trial. Pediatr Dent 2007;29:16-22. 
29. Kowash MB, Pinfield A, Smith J, Curzon ME. Effectiveness on oral health of a long-term health education programme for mothers with young children. Br Dent $\mathrm{J}$ 2000;188(4):201-5.

30. Rayner JF. Socioeconomic status and factors influencing the dental health practices of mothers. American Journal of Public Health 1970;6G:125Gi 258.

31. Bader JD, Rozier RG, Lohr KN, Frame PS. Physicians' roles in preventing dental caries in preschool children: a summary of the evidence for the U.S. Preventive Services Task Force. Am J Prev Med 2004 26(4):315-25.

32. Serwint JR, Mungo R, Negrete VF, Duggan AK, Korsch BM. Child-Rearing Practices and Nursing Caries. Pediatrics 993;92:233-37.
33. Beltran ED, Malvitz MM, Eklund SA. Validity of Two Methods for Assessing Oral Health Status of Populations. J Public Health Dent 1997;57(4):206-14.

34. Pierce KM, Rozier RG, Vann WF, Jr. Accuracy of pediatric primary care providers' screening and referral for early childhood caries. Pediatrics 2002;109(5):E82-2.

35. Wendt LK1, Koch G, Hallonsten AL. Parental awareness of dental caries in toddlers.Swed Dent J. 1996; 20(4):161-4.

36. Lee C1, Rezaiamira N, Jeffcott E, Oberg D, Domoto P, Weinstein P. Teaching parents at WIC clinics to examine their high caries-risk babies. ASDC J Dent Child. 1994 Sep-Dec;61(5-6):347-9. 